\title{
NAVIGATING THE TRANSITION FROM HIGHER EDUCATION TO THE LABOUR MARKET: A WAKE-UP CALL FOR UNIVERSITY STUDENTS
}

\author{
Peter J., WELLS ${ }^{1}$ and Silvia, FLOREA ${ }^{2}$ \\ UNESCO, France, p.wells@unesco.org \\ "Lucian Blaga” University of Sibiu, Romania, silvia.florea@ulbsibiu.ro
}

\begin{abstract}
Many studies describing the transition from school to work focus on national patterns of labour market entry and in so doing, they often simplify the complex transition processes and job finding requirements involved. Our paper sets out to look at some transition obstacles and paths from higher education to the labour market from the graduates' point of view as expressed during a recent event held at LBUS. We hold that in Romania the first job upon education is hampered by graduates across all disciplines having no or little work-based experience, thus marking national transition patterns/pathways as less compatible with those in other European countries.
\end{abstract}

KEY WORDS: higher education, graduate, transition, work, labour market

\section{INTRODUCTION}

In November 2015, the UNESCO Chair at "Lucian Blaga" University of Sibiu and the Bucharest Professional Training College, together with the Romanian Fulbright Commission and Ministry of Education organized an international conference in Sibiu under the umbrella title of "Lifelong Learning in Action: The university, employers, trainers and the community working together"[1]. The plenary session of the conference was dedicated to a panel dialogue between leading employers and students addressing the question: What experience[s] do employers look for when hiring university graduates?

Unanimously, all the employers agreed that they are looking for evidence of activities that demonstrate that an individual is reliable, dependable and creative, that he can use judgment, is resourceful, can work in a team, can show individual initiative, can lead others; can solve problems and propose solutions. In essence, employers want evidence of transferable skills - skills that cut across academic disciplines, study programs and subjects.

The students attending the conference were however equally unanimous in their response to the demands of today's employers: "This is a 'Catch 22' situation", they claimed: "How can we get the experience we need to get a job when we have to study fulltime before we qualify to even apply for a job?" And university students are not alone in this quandary with a similar complaint echoing around the corridors of many of today's high schools.

\section{TRANSITION OBSTACLES AND PATHS}

Several studies have shown that the transition from school to work is not so much an ordered sequence of first leaving school and then entering work, but rather a series of different activities that overlap and extend throughout adolescence and into young adulthood [2]. The return to education after gaining work experience or the transition from higher education to work, for example due to prolonged participation in education, phases of unemployment, or jobs with precarious contract conditions, may engender various consequences for the entire transition to adulthood [3]. A complex range of factors is generally associated with the ease or difficulty experienced by graduates in turning their expectations into reality. These factors are mixed and concern both employers and graduates, on equally opposing and complementing sides, and were voiced at the above mentioned event by such questions as: When is the best time during a study program to start looking for a job? What happens if a graduate does not secure an offer of skilled employment? If employers require work experience gained in a comparable workplace or labour market, then how can the new-to-the-field graduate lay claim to be the right candidate for an opening?

Indeed, things may get even more complicated if graduates are looking for jobs abroad and their work experience is assessed in terms of whether it was undertaken in any comparable labour market (for example in another European Union (EU) country). In such cases, the still difficult national transition patterns from education to work make it even more difficult for graduates to find a job abroad and will multiply this difficulty at a EU-wide level in what regards the graduates' work experience compatibility, job demand, job offer, required skills, to name only a few.

\section{WORK EXPERIENCE AND SKILLS}

The context and the depth of the discussions made it clear that the university (and high school) students need to appreciate the difference between a "job" and a "career", and they need to create their own life and work experiences outside their formal study programs. As the graduate labour market is 
increasingly stratified, particularly in areas where the supply of specialists and generalists exceeds demand, often times career planning, initiative and perseverance can become as significant as formal qualifications in determining how things will work out for the graduates. Academic and non-academic experiences (be they work-based or interest-based) are not mutually exclusive, they can and must happen in parallel if a graduate is to be successful in their ultimate career directions. In both the developed and developing worlds, students, teachers, and employers know that this is a vital element of preparing individuals for the world of work and for the collective sustainable growth of their respective economies.

A US census in 2011 showed that $71 \%$ of the nation's 19.7 million undergraduates were working while studying [4]. Similarly in the UK, a 2014 survey found that "the number of working students now stands at 59\%" [with] "nearly half of students $(45 \%)$ having a part-time job. $53 \%$ of these working students are doing so to "boost their employment prospects after university [5].

In attempting to define the nature of what these "employment boosting" work-based or transferable skills are for today's university graduates, the University of Sydney's Professor John Shields synthesized it expertly with a little help from one of the world's leading accounting and auditing institutions:

Our graduates are entering a professional labour market that is being revolutionized before our eyes. Technical knowhow - instant knowledge gratification - is available to anyone/everyone with access to the Internet. But enlightened employers know better than this. They know that graduates who can regurgitate definitions from textbooks are a dime a dozen. They also know that what sets a prospective graduate hire apart from the throng is a combination of up-to-date technical knowledge plus something far, far more important and difficult to substitute for. And what do they call this special set of qualities? They refer to them as 'client-facing' skills. [...] So what are "client facing skills" exactly? A PWC [Price Waterhouse Cooper] Report released February 2015 nailed it nicely. This report called "Data Driven: What Students Need to Succeed in a Rapidly Changing Business World" identified the following as critical future graduate skills:

4. Data analytics - not just chanting numbers but being able to craft a plausible narrative around the numbers - it's as much about words as numbers

5. Business acumen - a sharpness of thought and actions around business challenges and solutions

6. Creative thinking, curiosity and open-mindedness

7. Persuasive communication skills - the art of listening and arguing

8. Relationship skills

9. Leadership abilities - emotional and social intelligence; being cognizant of one's impact on others

10. And last but not least in the PWC attribute list: Global acumen - from having a mature understanding of how the world works, to building personal 'cultural dexterity' - or better still, 'ambidexterity”. [6]

Education can only go so far in developing these skills with students whether they are to become lawyers, entrepreneurs, doctors, secretaries, engineers, teachers, accountants, or policemen - such skills need to be practiced and honed outside of the classroom in the real world. Indeed, the move in higher education is clearly towards a stronger attention to employment prospects and the acquisition of core and transversal skills.
Therefore any form of part-time, weekend or summer/holiday job during studies demonstrates to a potential employer that a university graduate is reliable and resourceful. They show that they can work both in a team and independently. Work-based learning leads to exponential real experiences of problem solving, using initiative and exercising judgment - precisely the skills employers are crying out for. What is more, work experience does not have to be in an area related to a student's field of study. It is widely commonplace now for university students to have a diverse work experience background far removed from their studies or ultimate first career choice. It is not unusual for a high-flying investment banker to have worked as a cocktail waiter, a supermarket teller, and tour guide while at university.

A lack of workplace experience and the related skills and competences is one of the factors contributing to the "skills gap" in the EU today. "While 5.6 million young people in the EU suffer the consequences of unemployment, $36 \%$ of employers' reports that they struggle to find new recruits with the skills they need. Something is clearly wrong. The need to identify, adapt and adopt practices that can tackle this skills gap is urgent [7]. In many countries the non-career/nonprofessional work experience versus the very professional/career study program is often a difficult one to reconcile. How can, for example, an IT undergraduate possibly benefit from working part-time or during the summer vacation at a fast food chain? The truth is, that it is not where the 'student job' a student of IT takes him/her, but about the workbased skills that she/he learns from that experience experiences which they cannot or do not acquire from a university study program and which, regardless of the thousands of hours (and dollars) they invest in their studies they will need to become the next Steve Jobs. They will have plenty of time (at least 40 or more years) for their careers in ITC after they graduate, but in order to kick off their debuts on the labour market, it will be the "other experiences" that will count the most when trying to secure a good first career position upon graduation.

It is not all about students earning money to support themselves through their higher education. Non-paid internships and workplacements are equally important. Students often berate their institutions for not 'arranging' internships for them, when in reality it is ultimately up to the student (ideally with the support of their institution - with or without official study credit recognition) to set up and arrange their own internships. The authors are aware of an 18 year-old high school leaver who walked into Saatchi and Saatchi in London and told the HR Manager "I am going to work for you for free for six months and then you're going to hire me!" And they did.

It is not only work-experiences that count. CV 'experience building' is also now more important than ever in taking on extra-curricular activities, both inside and outside of formal education and both for entering the labour market and securing places on Master's and Doctoral programs. The report from the UK states that, " $41 \%$ of those who take part in extracurricular activities do so to boost their employment or further education prospects" because employers and universities consider all types of experience as vital in assessing the character of an applicant: volunteering at the local school or hospice; coaching the local basketball team; babysitting for friends and family; even being a part of the organizational team of a conference like the one in Sibiu - and hundreds more activities are all considered essential by employers when deciding on whom to hire from a thousand faceless graduate CVs with the same 
degrees, the same grades and frequently the same alma maters.

Unfortunately, parents and guardians in many countries often bear much of the responsibility for the lack of work-based experiences in their student offspring, by urging them to concentrate on their studies instead of getting a part-time job or a finding an internship believing that employers only want to hire graduates with the top grades. In reality, quite the reverse is true: Employers know that graduates already have a sound technical knowledge by virtue of them having actually graduated. The best employers would want more than that, and the best university graduates are those with more to offer than just graduating top of their class.

It is not important where a student works, volunteers or where they do their internship(s) providing it makes them stand out from the crowd and allows them to demonstrate a good work ethic and a real passion for something - anything. Colin Lovering, Chairman of the British Chamber of Commerce in Romania and speaker at the Sibiu conference, likened this to the difference between gift-wrapping a present versus presenting it in a ubiquitous supermarket plastic bag. Philip Walters, Vice-Principle of the British School of Bucharest and speaker at the same event, called it "graduates having the courage and conviction to be different".

\section{CONCLUSIONS}

In various forms and voices but attuned to the same concerns, the event and the discussions at various levels helped shape the idea that structural change is needed to create and develop a variety of high-quality work-based learning forms and opportunities, involving the redesigning of higher education curricular to require and recognize work-place based learning in academic programs, as well as the long-term commitment by employers, social partners and policymakers to compliment the initiatives of higher learning institutions. As pointed out by graduates of the Sibiu conference, the benefits for individuals, enterprises and indeed society at large are significant. Shortterm results can also be obtained by investing in other forms of work-based learning, notably on-the-job-traineeships and real life project assignments and workshops in schools apt to support a smooth transition from learning to work.

\section{ACKNOWLEDGMENT}

Several passages from this paper were adapted from an online commentary (Peter J. Wells, www.republica.ro, NovemberDecember 2015).

\section{REFERENCES}

1. "Lifelong Learning in Action: The university, employers, trainers and the community working together" (November, 2015), available

at: http://conferences.ulbsibiu.ro/unesconcw/en/

2. Jacob, Marita, and Weiss, Felix, (2008), From Higher Education to Work: Patterns of Labor Market Entry in Germany and the US, Mannheim.

3. Hillmert, Steffen and Jacob, Marita, (2004), " Multiple episodes: training careers in a learning society", in Globalife Working Paper, Bamberg: Otto-Friedrich University of Bamberg.

4. O’Shaughnessy, L., (2013, February 5), More Students Working (a lot) in College, CBS News. Retrieved from http://www.cbsnews.com/news/more-students-working-alot-in-college/

5. Gil, N., (2014, August 11), One in Seven Students Work Part-time, The Guardian. Retrieved from: http://www.theguardian.com/education/2014/aug/11/stude nts-work-part-time-employability

6. Shields, J., (2015, November 3), Cultural Competence The New Imperative in Graduate Hiring. Retrieved from: https://www.linkedin.com/pulse/cultural-competence-newimperative-graduate-hiring-john-shields?

7. European Commission, Education and Training (2013), Work-Based Learning in Europe, Practices and Policy Pointers, p.32. Retrieved from: http://ec.europa.eu/education/policy/vocationalpolicy/doc/alliance/work-based-learning-in-europe_en.pd 